J. Dairy Sci. 92:4101-4111

doi:10.3168/jds.2009-2326

(c) American Dairy Science Association, 2009.

\title{
Invited review: The welfare of dairy cattle-Key concepts and the role of science
}

\author{
M. A. G. von Keyserlingk, ${ }^{* 1}$ J. Rushen, $†$ A. M. de Passillé, $†$ and D. M. Weary* \\ *Animal Welfare Program, University of British Columbia, 2357 Mall, Vancouver, British Columbia, Canada, V6T 1Z4 \\ †Agriculture and Agri-Food Canada, PO Box 1000, Agassiz, British Columbia, Canada, V0M 1A0
}

\begin{abstract}
Concerns about the welfare of animals typically include 3 questions: is the animal functioning well (e.g., good health, productivity, etc.), is the animal feeling well (e.g., absence of pain, etc.), and is the animal able to live according to its nature (e.g., perform natural behaviors that are thought to be important to it, such as grazing)? We review examples, primarily from our own research, showing how all 3 questions can be addressed using science. For example, we review work showing 1) how common diseases such as lameness can be better identified and prevented through improvements in the ways cows are housed and managed, 2) how pain caused by dehorning of dairy calves can be reduced, and 3) how environmental conditions affect cow preferences for indoor housing versus pasture. Disagreements about animal welfare can occur when different measures are used. For example, management systems that favor production may restrict natural behavior or can even lead to higher rates of disease. The best approaches are those that address all 3 types of concerns, for example, feeding systems for calves that allow expression of key behaviors (i.e., sucking on a teat), that avoid negative affect (i.e., hunger), and that allow for improved functioning (i.e., higher rates of body weight gain, and ultimately higher milk production).

Key words: animal welfare, dairy cattle, cow, calf
\end{abstract}

\section{INTRODUCTION}

Concern about animal welfare is nothing new; producers have always been concerned about the condition of animals in their care and have tried to ensure that they are healthy and well nourished. In this tradition of animal care, good welfare is seen largely as the absence of illness or injury. More recent concerns about animal welfare have focused on the pain or distress that the animals might experience as a result of widely accepted

Received April 25, 2009.

Accepted June 2, 2009.

${ }^{1}$ Corresponding author: marina.vonkeyserlingk@ubc.ca management practices, and the possibility that animals suffer as a result of being kept under apparently "unnatural" conditions (Fraser, 2008). Over the past decade, there has been a blossoming of scientific research on the welfare of cattle to address these issues (for an in-depth review, see Rushen et al., 2008). In this review, we discuss some of the diversity in the animal welfare challenges facing the dairy industry and illustrate the role of science in addressing these challenges.

\section{WHAT IS ANIMAL WELFARE?}

People's concerns about farm animal welfare focus on 3 broad questions: 1) is the animal functioning well, 2 ) is the animal feeling well, and 3) is the animal able to live a reasonably natural life (Fraser et al., 1997)? Those caring for the animals are naturally concerned about the first category, addressing issues such as disease, injury, poor growth rates, and reproductive problems that are bad for the animal and also for the viability of the farm. However, many people are also concerned with the affective (emotional) state of the animal and focus on whether the animals are suffering from unpleasant feelings, such as pain, fear, or hunger, or whether they are experiencing positive states, such as pleasure associated with play. For others (including many consumers of organic products), a key concern is whether the animal is able to live a relatively natural life and can express natural behavior. These 3 aspects of animal welfare are usually included in official definitions; for example, the World Organization for Animal Health defines an animal as being in good animal welfare if it is "healthy, comfortable, well nourished, safe, able to express innate behavior, and . . . is not suffering from unpleasant states such as pain, fear, and distress" (World Organization for Animal Health, 2008).

These different types of concerns about animal welfare can and do overlap (Figure 1). A lactating dairy cow unable to seek shade on a hot day (natural living) will likely feel uncomfortably hot (affective state) and may show signs of hyperthermia, and ultimately reduced milk production (poor biological functioning). Lameness is another example of how these 3 animal 


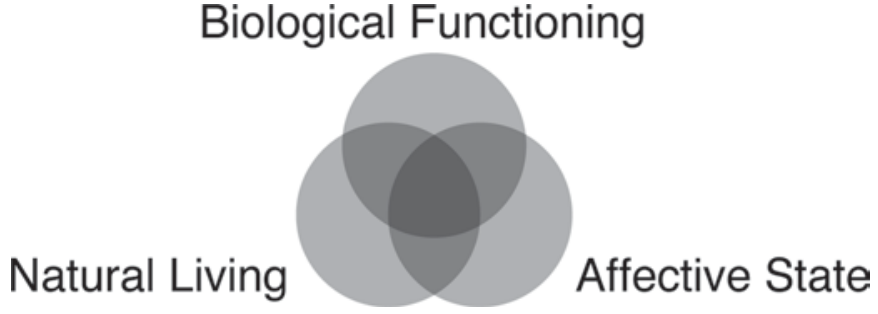

Figure 1. Three overlapping areas of welfare concern. Redrawn from Fraser et al. (1997).

welfare concerns overlap. A lame cow is in pain (affective state), has lower milk production and reproduction (poor biological function), and has reduced mobility (natural behavior). Furthermore, from an animal welfare perspective, much of the concern about disease arises from the suffering that the animal undergoes because of illness. In such cases, improvements in one aspect of animal welfare (e.g., reduced physiological signs of hyperthermia) will probably result in improvements in the other aspects (reduced feelings of discomfort). In other cases, the different concerns may appear to be in conflict. For example, concern about the effect on dairy calves of a lack of social contact has led the European Union basically to outlaw individual housing for calves older than 8 wk. Housing dairy calves in groups allows them to engage in natural social interactions, but when poorly managed, this can lead to increased incidence of certain diseases or aggression. Different people can thus reach opposite conclusions about the relative welfare advantages of different housing systems by favoring different welfare indicators (Fraser, 2003).

Scientists have reacted to the diversity of views on animal welfare by trying to develop a scientific concept that is most amenable to scientific investigation, but the relative weight given by different people to different aspects of animal welfare reflects their personal values, and science alone cannot impose a "correct" definition (Fraser, 2008); failure to address the full range of concerns the public has about animal welfare will not resolve this issue. A powerful illustration of these contrasting perspectives comes from the debate around California's Proposition 2. This 2008 ballot initiative, passed with $63.4 \%$ of the vote and enacted as California's Prevention of Farm Animal Cruelty Act, prohibits the confinement of veal calves, laying hens, and swine for the majority of every day in a manner that does not allow them to turn around freely, lie down, stand up, and fully extend their limbs. Most affected are the laying hens currently housed in battery cages. Opponents of this proposition emphasized that the current housing was developed to promote bird health (and egg quality) by reducing exposure to feces - in other words, to promote good biological functioning. However, for the supporters of the proposition (and apparently for most Californians), this was not enough. They believed that birds must also be allowed enough physical freedom to perform a few key behaviors. Indeed, most of the animal welfare legislation that has been enacted in the European Union and around the world has focused on painful procedures and on allowing animals a greater degree of behavioral expression (Veissier et al., 2008). We suggest that the lessons learned from Proposition 2 are also relevant for dairy cattle welfare. Housing and management systems for dairy cattle not only must meet the traditional concerns around good biological functioning, but also must address other key elements of animal welfare that are important to the public and to consumers of dairy products.

We urge readers to be skeptical of proposed solutions to welfare problems that address only one type of concern (e.g., calf health) while creating or accentuating another (e.g., social isolation). Clearly, the best solutions will be those that address all 3 concerns, for example, by creating group-housing systems for calves that avoid competition, allow for social contact, and keep calves healthy. In this way, the 3 types of concerns can be considered as a checklist to guide researchers in identifying and solving the various dairy cattle welfare issues. Research alone may not tell us which types of concerns are the most important, but it can and has identified issues within each of the 3 areas of concern, and has helped to provide solutions to these issues. Below, we review examples of recent work showing how science can be used to address dairy cattle welfare issues from the perspectives of biological functioning, natural living, and affective states.

\section{HEALTH AND BIOLOGICAL FUNCTIONING}

That good health is central to good welfare is relatively uncontroversial. Measures of biological health used by veterinarians and producers generally focus on disease, injury, and reproductive problems. Problems in biological functioning are clearly a welfare concern in many cases. For example, high rates of mortality are almost always associated with a poor quality of life for the animals. Surveys continue to report high levels of mortality in milk-fed calves (USDA, 2007), and clearly both the calves and the producers would benefit from reduced mortality rates. The challenge here is to get improved management procedures onto those farms that need them most.

Morbidity or mortality should be considered only as a crude indicator of health and welfare. Assessing animal health through the use of more sensitive indicators, which are suitable for use before animals are clinically 
ill or dying, should greatly reduce the risk of suffering as a result of disease. Below, we provide 2 examples of research that developed sensitive, early indicators of cow health.

\section{Lameness}

Lameness is widely regarded as a major welfare problem for dairy cows. Lameness can result from infectious disease (such as digital dermatitis and foot rot) or from lesions caused by disruptions of the horn of the claws (e.g., ulcers, hemorrhage, white line separation). Management factors, such as the use of concrete floors, zero grazing, and uncomfortable stalls, are important risk factors underlying the large differences between farms in the incidence of lameness (reviewed by Cook and Nordlund, 2009).

Unfortunately, producers find it difficult to identify animals in the early stages of lameness (Whay et al., 2003). Many gait-scoring methods suffer from a lack of detail regarding the specific changes in gait expected to occur as cows become lame, or they rely on only one or a few specific changes in gait, such as an arched back; these features may make these methods easier to use but they potentially compromise reliability and validity (e.g., Channon et al., 2009; Tadich et al., 2009). One problem in developing good gait-scoring systems is that we have few good scientific descriptions of how healthy cows walk. Better scoring systems will require improved knowledge of the gait of cows, and this can be derived from computer-assisted kinematic techniques that obtain precise measures of gait and how this changes with different types of hoof injuries (Flower et al., 2005). Our group uses a gait-scoring system based on several specific gait features (e.g., asymmetric steps, tracking up, etc.) that we have identified as occurring when cows develop hoof lesions. The resulting gait scores have proved to be sensitive in identifying cows with sole ulcers, and they show the effects of pain reduction after use of a local anesthetic or nonsteroidal antiinflammatory drug and the advantages of softer walking surfaces for lame cows (reviewed by Flower and Weary, 2009).

Part of the difficulty in early lameness detection may come from the fact that herd sizes are increasing, leaving producers less time to spend watching their animals. Furthermore, some hoof lesions do not appear to result in observable changes in gait (Tadich et al., 2009), suggesting that automated measures of other behavioral consequences of hoof lesions, such as time standing and lying or walking time, may be needed. The increasing use of on-farm automation (e.g., milking equipment, grain and milk feeders, scales) provides a vast opportunity for collecting data relevant to the health of cows and calves. Automated detection of lameness is particularly promising: lame cows can be identified by changes in the way they distribute their weight between their legs when walking or standing (Pastell and Kujala, 2007), by automated image analysis (Song et al., 2008), and by the number of times they visit automated milking systems (Borderas et al., 2008a). Automated measures have the added benefit of not requiring the presence of human observers; the human presence itself may increase the likelihood of animals masking any vulnerability (Weary et al., 2009). Automated detection of other illnesses besides lameness also appears feasible. Below, we describe examples from our recent research showing how automated measures of feeding behavior and intake can be use to identify disease in transition cows.

\section{The Transition Cow}

In the weeks after calving, cows are at a high risk for both metabolic and infectious disease (Ingvartsen et al. 2003). These transition diseases result in an important economic loss for producers and are one of the most serious welfare issues affecting dairy cows. The high prevalence of infectious disease may be linked to inadequate nutrition (Goff, 2006), which may also contribute to a depression of the immune system during transition (e.g., Hammon et al., 2006). A key area for welfare-related research has been in the development of early indicators of these diseases, particularly those related to feeding.

Because some diseases are typically detected only during routine herd health checks done by the herd veterinarian, many diseases may go undiagnosed between clinical examinations. Although producers can use urine, milk, or blood tests to monitor the health of their animals, frequent administration of tests on a herd-wide scale can be costly and time-consuming, suggesting a need for more rapid monitoring that can be done continuously.

In more recent years, there has been an explosion of interest in behavioral indicators of disease following the development of a new conceptual perspective (reviewed by Millman, 2007). Behaviors shown by ill animals are part of a coordinated strategy to fight disease. The behavioral changes attributable to illness are controlled by cytokines of the immune system and so appear to be part of the immune response to illness. Injections of bacterial endotoxin are sufficient to produce many of the behavioral changes that occur during infectious illness, such as reduced activity, feeding, grooming, and rumination in dairy calves (Borderas et al., 2008b). A better knowledge of sickness behavior in cattle will help improve our ability to detect illness earlier, especially when animals are housed in large groups. 


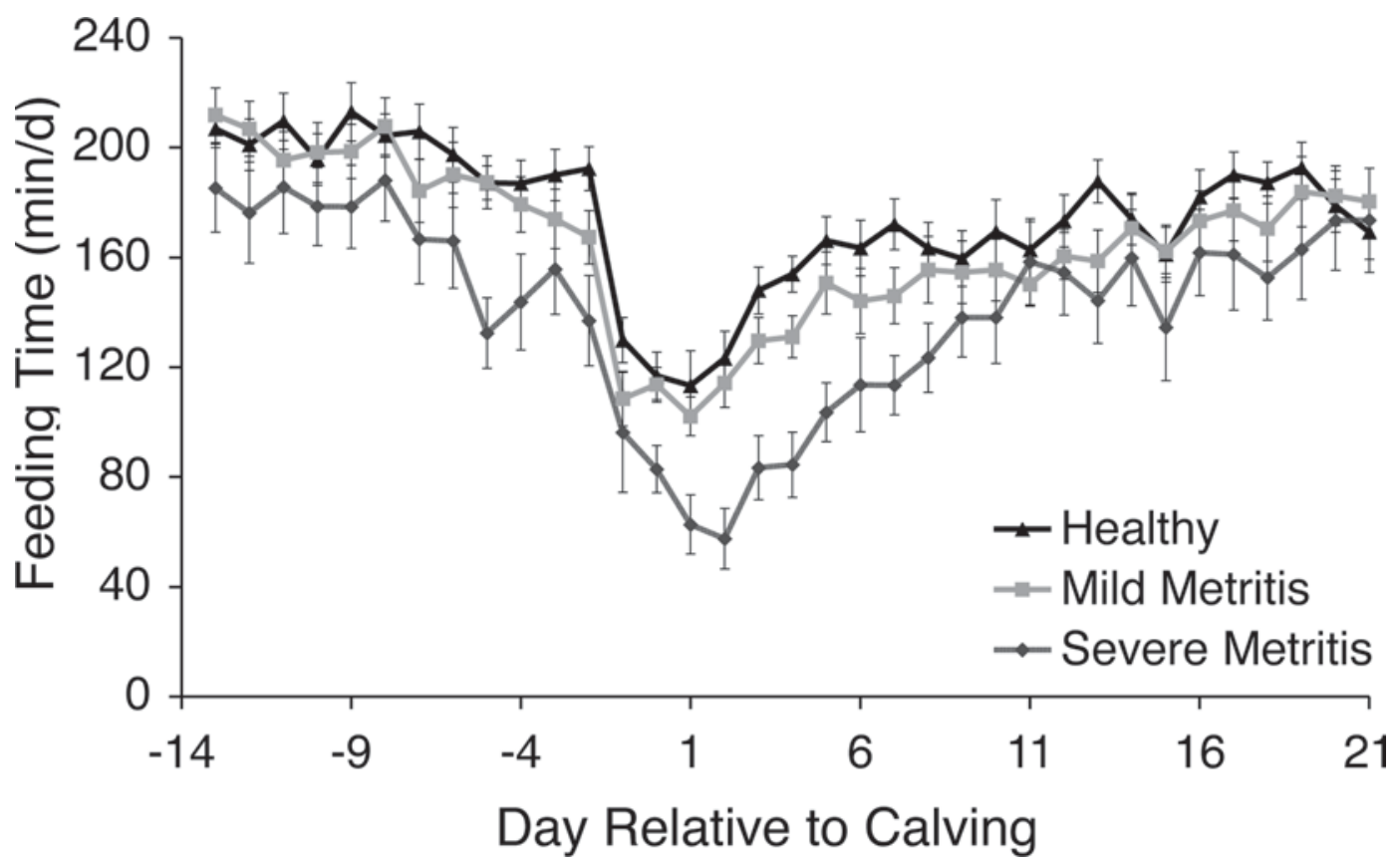

Figure 2. Average feeding time ( $\mathrm{min} / \mathrm{d}$ ) of healthy, mildly metritic, and severely metritic Holstein dairy cows from $13 \mathrm{~d}$ before until $21 \mathrm{~d}$ after calving. Redrawn from Huzzey et al. (2007).

Our own work has focused on identifying cows at risk for metritis, in part because of the high incidence and negative effects on reproductive performance, and in part because the importance of metritis for animal health and welfare has been underemphasized compared with mastitis and lameness. Huzzey et al. (2007) found that cows diagnosed with metritis spent less time feeding during the precalving period than did their healthy counterparts; every 10-min decline in prepartum feeding time was associated with a 2-fold increase in the chance that a cow would be diagnosed as suffering from metritis. These results indicate that changes in feeding behavior can be a sensitive indicator of this disease (Figure 2). We do not yet know whether the changes in feeding behavior are a cause or a result of metritis, or whether they reflect some other factor that predisposes the cow to becoming ill, but Huzzey et al. (2007) shed some light on possible mechanisms. During the week before calving, cows that were later diagnosed with severe metritis engaged in fewer aggressive interactions at the feed bunk (i.e., displaced others from the feed bunk less often) and had reduced feeding times as well as intakes during the periods after fresh feed delivery, a time when cows are normally highly motivated to eat. Cows that were diagnosed with severe metritis after calving therefore appeared to be less motivated to compete for access to the feed before calving. This lack of motivation may indicate that these cows are socially subordinate and unwilling to engage in interactions with more dominant individuals. More recent research has shown that automated monitoring of changes in feeding behavior may be able to detect a variety of acute transition diseases (González et al., 2008). Together, this research shows that monitoring feeding behavior may give producers a better chance of detecting transition cow illness at an early stage. Indeed, automated monitoring of feeding behavior can be helpful in detecting illness in a range of other situations, including disease in milk-fed calves (Svensson and Jensen, 2007).

\section{Animal Productivity}

It is often assumed that poor welfare will be apparent in low milk production and that high levels of milk production should indicate good animal welfare. There are good reasons why problems causing poor welfare can lead to lower productivity. Activation of the immune system during an illness requires metabolic energy (Colditz, 2002) and illness often results in reduced feed intake; thus, resources may be limited and may be diverted into immune function rather than milk production, growth, or reproduction. For lactating cows, several studies have estimated the reduction in milk yield associated with various diseases (e.g., Gröhn et al., 2003). For example, Huzzey et al. (2007) showed that cows that became ill with metritis produced approximately $8 \mathrm{~kg} / \mathrm{d}$ less milk during the first $3 \mathrm{wk}$ of lactation. Clearly, a decline in milk production can be 
indicative of illness. Short-term changes in milk yield have also proven useful in assessing cows' responses to stressful events. For example, a variety of acute stressors, such as novel surroundings, can reduce oxytocin secretion, leading to blocked milk ejection and hence reduced milk yield (e.g., Bruckmaier and Blum, 1998). In these circumstances, the observed decline in milk yield can be seen as an indicator of reduced welfare.

However, much variation in milk yield is unlikely to be related to differences in animal welfare. Milk yield can be affected by nutritional, genetic, and environmental factors that are welfare neutral, and high levels of production may increase the risk of certain welfare problems. High production (among pigs, poultry, and cattle) is associated with an increased risk of health problems (reviewed by Rauw et al., 1998). Improved genetics and nutrition have resulted in a 2 to $3 \%$ increase in milk production per cow per year in Western countries, but this increased production puts extra demands on the cow, likely leading to an increased incidence of disease and higher rates of involuntary culling (e.g., Kelm et al., 2000; Fleischer et al., 2001). The specifics of this issue are beyond the scope of this article, but Ingvartsen et al. (2003) and Rauw et al. (1998) provide useful discussions. Because of the complex relationship between milk production and animal welfare, few animal welfare experts consider milk yield to be a useful measure in on-farm welfare assessments of dairy cattle (Whay et al., 2003). The important point is that a high level of milk production is no guarantee of high welfare, nor is a low level of production to be taken as an automatic sign of poor welfare.

\section{AFFECTIVE STATES}

How animals feel is a central issue in animal welfare. Although once thought to be beyond the scope of science, understanding mental states in animals is now an active area of research (Dawkins, 2008), and developing validated measures of these states remains one of the most interesting problems in animal welfare science. Although the majority of the work to date has focused on negative affect (e.g., pain and suffering), some newer research is now examining positive mental states in animals (Bertenshaw et al., 2008). Boissy et al. (2007) provide an excellent review of positive affect in animals.

Compared with other emotions such as fear and anxiety, considerable progress has been made in understanding and measuring animal pain, and a large and rapidly developing body of scientific literature on pain assessment and prevention in now available for farm animals (reviewed by Weary et al., 2006). Procedures such as dehorning are routinely performed on dairy cattle without the benefit of pain relief, so it is important to have well-established methods of assessing any pain that results and to develop methods of preventing this pain. Below, we focus on 2 examples, dehorning and tail docking.

\section{Dehorning}

Considerable research has shown that all methods of dehorning and disbudding cause pain to calves, and this can be shown with a variety of physiological and behavioral measures (reviewed by Stafford and Mellor, 2005). It is now also becoming clear that use of a local anesthetic alone does not fully mitigate this pain, and does not provide adequate postoperative pain relief. The most popular local anesthetic, lidocaine, is effective for 2 to $3 \mathrm{~h}$ after administration, and calves treated with a local anesthetic have similar plasma cortisol levels as untreated animals after the local anesthetic loses its effectiveness (Stafford and Mellor, 2005). However, the use of nonsteroidal antiinflammatory drugs (such as ketoprofen), in addition to a local anesthetic, can keep plasma cortisol and behavioral responses close to baseline levels in the hours that follow disbudding and dehorning. More powerful analgesic drugs are becoming available, which hold further promise for pain control during procedures such as disbudding (Heinrich et al., 2009). A second consideration is that animals respond to both the pain of the procedure and to the physical restraint. Calves disbudded using a local anesthetic still require restraint, and calves must also be restrained while the local anesthetic is administered. The use of a sedative (such as xylazine) can essentially eliminate calf responses to the administration of the local anesthetic and to the need for physical restraint during administration of the local anesthetic and during disbudding. Thus, a combination of a sedative, local anesthetic, and nonsteroidal antiinflammatory drug reduces the response to pain during disbudding and in the hours that follow.

One common alternative to hot-iron disbudding is using caustic paste to cause a chemical burn. This method is still painful for the calves (Stilwell et al., 2009), but the pain appears easier to control. Calves treated only with the sedative xylazine showed no immediate response to application of the paste and showed little response in the hours that followed (Vickers et al., 2005). Moreover, disbudding in this way (i.e., caustic paste combined with a sedative) actually resulted in less pain to calves than disbudding with a hot iron combined with both a sedative and a local anesthetic. This example shows how research can provide clear answers to questions about the painfulness of routine procedures and how methods of pain treatment can be 
developed that are both effective and practical for use on farm.

\section{Tail Docking}

Tail docking dairy cows has become popular in North America; the 2007 National Animal Health Monitoring System survey showed that $39 \%$ of cows have docked tails (USDA, 2009). Several studies have examined the effect of tail docking on the welfare of dairy cattle. There is evidence of acute pain associated with docking, but no clear evidence that the use of anesthetics, or performing the procedure at younger ages, reduces the pain response (Tom et al., 2002a,b). Moreover, tail docking may result in chronic pain. Sectioning the nerves in the tails of cattle can result in neuroma formation; neuromas can cause chronic pain, similar to the phantom pain felt after limb amputation (Eicher et al., 2006).

The issue of tail docking differs from dehorning not only in terms of pain and pain control, but also in the benefits to the animals and the farm. Few disagree that intensively reared cattle should be kept without horns: the horns of cattle can be a threat to workers and other animals if these horns are not removed. The benefits of tail docking are less clear. Multiple large-scale controlled experiments have shown that docking tails provides no systematic advantage in terms of cow cleanliness or udder health (Schreiner and Ruegg, 2002). Given the obvious disadvantages to the cow, including a reduced ability to control flies, there seems to be little reason for continuing this procedure.

We have focused on pain, in part because the research results are clear, but also because there is widespread consensus regarding the ethics of intentionally causing or failing to prevent pain to animals. However, we urge readers not to focus only on pain; other affective states may be equally or more detrimental to animal welfare, such as the fear associated with poor handling practices and facilities (Rushen et al., 2008), or positive affective states such as pleasure associated with play (Boissey et al., 2007). Cattle can be surprisingly sensitive to subtle stressors: even a few minutes alone in an unfamiliar environment are enough to provoke substantial increases in cortisol secretion, heart rate, and vocalization and block milk ejection (Rushen et al., 2001).

\section{NATURAL LIVING}

We have left the natural living aspect of animal welfare to the end, in part because it is conceptually the least clear, and in part because this is the animal welfare issue that causes the animal industries the most difficulty. However, the "unnaturalness" of mod- ern housing conditions is one of the greatest sources of public concern, so dairy scientists need to find effective ways of addressing this issue. For some, the natural living criterion is clear - simply allowing animals to live as naturally as possible. We see this approach as naïve; some natural conditions, such as exposure to climatic extremes, disease, parasite infections, and predator attacks, cannot be good for the animals (Špinka, 2006). Furthermore, given the genetic changes that have occurred among cattle because of artificial selection, there is great difficulty in deciding what their natural life is (Rushen et al., 2008). Thus, we need to know which aspects of the natural life are really important to animals, how this might be evaluated, and whether any benefits can be achieved in a more practical way. We use the examples of ad libitum feeding for calves and pasture access for cows to illustrate how research can determine if access to more natural environments can provide benefits to the animals.

Allowing cattle to live a reasonably natural life could seem to require practices perceived as impractical or uneconomical, such as leaving cows and calves together. Thus, a key role for research in this area is also to discover ways of providing key features to the animals that are practical for producers.

\section{Feeding and Housing for Calves}

Methods of feeding calves in modern dairying differ markedly from those found in nature (von Keyserlingk and Weary, 2007), but knowing more about the natural behavior of cow-calf pairs can help us develop better ways of feeding calves. Traditionally, calves are fed milk twice daily at $10 \%$ of BW, but calves often fail to gain BW during the first days of life (Hammon et al., 2002). When provided the opportunity to suckle from the dam, calves consume considerably more than $10 \%$ of their BW and grow much more rapidly than with conventional feeding (Flower and Weary, 2003). However, this benefit can be achieved without keeping the cow and calf together. It is now clear that feeding milk to allow higher intakes leads to higher BW gains, improved feed conversion efficiencies, and reduced age at first breeding (Diaz et al., 2001; Shamay et al., 2005). Thus, a better understanding of the natural behavior and preferences of the calf has revolutionized calf feeding practices, providing benefits to the calf and producer.

Feeding higher levels of milk also benefits the calf by making it less hungry. Calves vocalize when hungry, and this vocal response, even in the first days after separation from the cow, can be greatly reduced or eliminated by providing more milk or colostrum (Thomas et al., 2001). Calves that are fed restricted amounts of milk from an automated calf feeder typically visit the feeder 


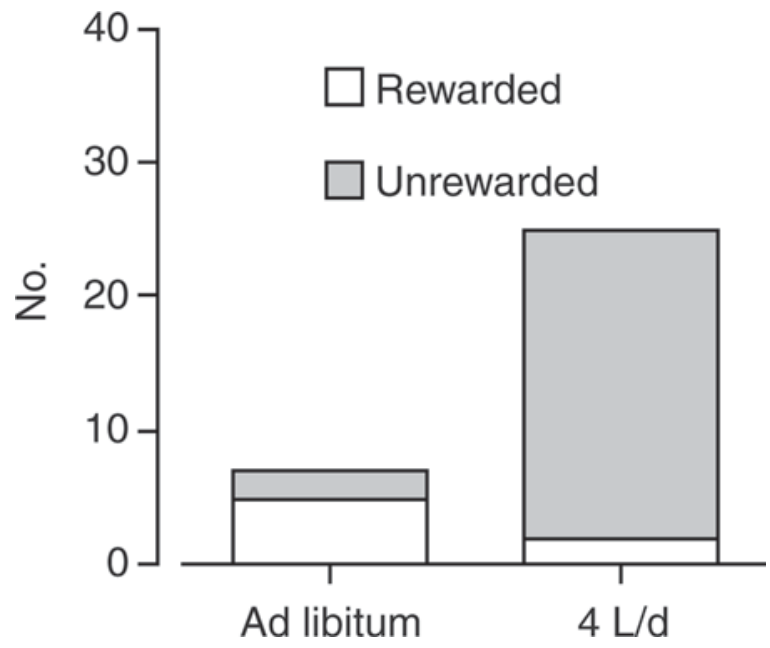

Figure 3. Number of rewarded and unrewarded visits per day by calves fed milk ad libitum or $4 \mathrm{~L} / \mathrm{d}$. Redrawn from Vieira et al. (2008).

more than 20 times a day, even when they receive milk on only 2 of these visits. Increasing the milk ration greatly reduces the frequency of these unrewarded visits (Jensen, 2006; Vieira et al., 2008; Figure 3). This reduction benefits the other calves using the feeder by reducing feeder occupancy and competition for feeder access. Thus, allowing more natural feeding behavior reduces hunger and, in this case, also improves the efficiency of the feeding system, thus facilitating group housing of calves.

The studies cited above suggest that the benefits of keeping the cow and the calf together in terms of improved growth and reduced hunger can be achieved at least in part by simply providing calves more milk. Nipple feeding is more natural, but does this provide additional benefits for the calf? Calves allowed to suck on a teat during or after a meal show higher concentrations of cholecystokinin and insulin (de Passillé et al., 1993) and a greater degree of relaxation after the meal (Hänninen et al., 2008). Group-housed milk-fed calves will sometimes suck each other (i.e., cross-sucking), but this cross-sucking can be greatly reduced or eliminated if calves consume their milk ration via free access to a teat, likely because the sucking behavior, rather than the ingestion of milk, is responsible for reducing sucking motivation (de Passillé and Rushen, 2006). If used in conjunction with automated feeding systems, nipple feeding also facilitates group housing, saving labor for producers (Kung et al., 1997) and perhaps providing other benefits to the calves. Young calves are highly motivated to seek social contact (Færevika et al., 2007), and early social contact may allow calves to better develop their social skills, which are useful later in life.
This example shows how an understanding of natural behavior can help inform the design and management of feeding systems that provide multiple benefits for calves and the people who care for them.

\section{Pasture Access for Dairy Cows}

Dairy cattle allowed access to pasture are sometimes perceived as having higher welfare because the animals have freedom to express natural behaviors, such as grazing and exploration (Hemsworth et al., 1995). But do cattle really prefer pasture, and are there any health benefits with pasture access? We review 2 examples below. One shows that cows do sometimes prefer access to pasture over access to a free-stall barn, but that this preference is complex and is sometimes reversed depending on environmental conditions. The second example shows that even short-term access to pasture can provide certain health benefits to cows.

Perhaps the simplest way of assessing how animals feel about their housing is to provide them a choice (Fraser, 2008). Preference tests allow the animal to vote with its feet, telling us which option the animal judges to be best. Of course, this tells us only about the relative ranking; both options might be quite good or quite poor. In addition, we all can make bad choices (i.e., prefer options that are not in our long-term interests). Still, preference tests provide a relatively straightforward way of asking animals about their preferred environments, and in many situations, allowing animals access to a preferred option can provide welfare benefits.

In one recent study, cows were allowed free-choice access either to a well-designed and managed free-stall barn or to an area of pasture adjacent to the barn (Legrand et al., 2009). When provided the choice, cows did indeed prefer the pasture, but only at night (Figure 4); during daylight hours, cows returned to the barn, especially when temperatures were warm. Thus, the pattern of preference is complex - cows did prefer access to pasture, but only under some conditions, and they were likely using the 2 options in different ways. For example, the free-stall barn was likely attractive during warm days because it provided shade that was not available on the pasture; the use of shade by cattle is directly related to solar radiation (Schütz et al., 2009). Cows also returned indoors to access the TMR that was available only inside. More work is required to understand how preferences change under different conditions. Providing the cows a choice may be part of the solution because this allows cattle to pick the environment that best suits their variable needs. Future preference research might also show how both options could be improved. For example, would cows prefer to 


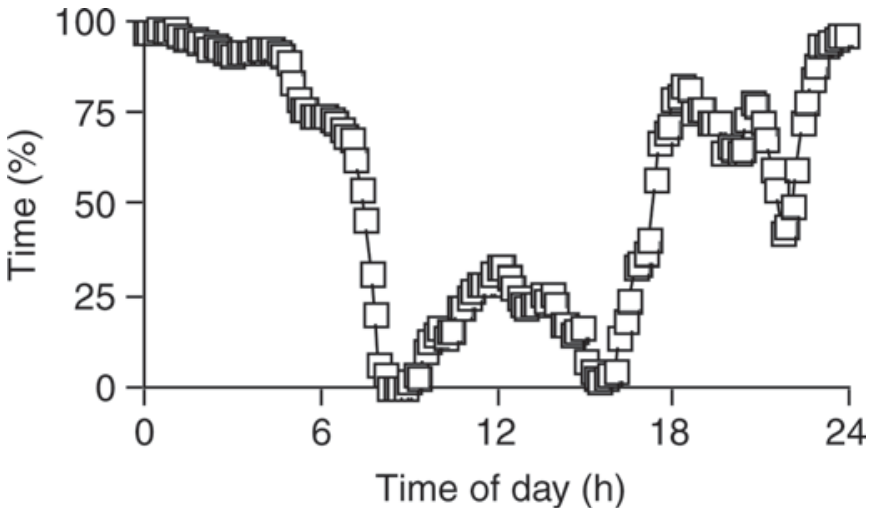

Figure 4. Percentage of time cows spent on pasture when allowed free access between a free-stall barn and adjacent pasture. Redrawn from Legrand et al. (2009).

remain on pasture, even during warm days, if shade were available?

Several examples in the literature show how access to pasture can improve aspects of cow health such as mastitis (Washburn et al., 2002). Providing continuous access to pasture can be challenging for many dairy farmers, but access is often possible for at least some cows during some parts of the year. If pasture does have health benefits, one approach might be to target cows that are ill or at risk of becoming ill. With this in mind, Hernandez-Mendo et al. (2007) provided lame cows with short-term (5-wk) access to pasture. Cows on pasture improved in gait rapidly relative to their matched controls (i.e., those with identical gait scores at the beginning of the study, but kept in a free-stall barn); by the end of the pasture period, cows on pasture scored, on average, only 2 on a 5 -point scale of gait, but the control cows scored more than 3 on the same scale. These results should not be taken to mean that pasture access will improve all measures of health or functioning, or even that it will improve lameness in all conditions. Indeed the incidence of lameness can be high in pasture-based dairying systems under certain conditions (e.g., if tracks are poorly maintained; Lean et al., 2008). However, this example illustrates that providing access to more natural living conditions can have important benefits for animals under the right conditions.

Studies of natural living can also provide insights into which specific environmental features may be important to the cows. For example, the study by HernandezMendo et al. (2007) showed that cows actually spent more time standing (and thus less time lying down) when kept on pasture, suggesting that access to suitable standing surfaces plays an important role in allowing lame cows to recover. The use of concrete floors has been identified as a risk factor for increased claw lesions and lameness (Vanegas et al., 2006), so cows may benefit from pasture because it allows them to avoid standing on concrete flooring. In a recent study, Bernardi et al. (2009) modified the free-stall housing by moving the neck rail, allowing cows to spend time standing inside the free stall rather than fully or partially on the concrete flooring outside the stall. This one change to an existing facility had effects similar to that observed in the pasture study; lame cows recovered after a few weeks of access to the modified stall. Thus, insights from studies of cows kept under more natural conditions can lead to beneficial changes in the design and management of intensive production systems, even when these changes do not make the intensive systems look any more natural. Similarly, some changes in management and facility design can reduce the frequency of behaviors that may be natural but unwanted in intensive production systems, as described below.

\section{Reducing the Frequency of Unwanted Behaviors}

Some natural behaviors that are likely important to the cow are unwanted on the farm. In these cases, it is important to understand what housing or management features can provoke or reduce the occurrence of these behaviors. Examples include high levels of maternal protectiveness by cows (von Keyserlingk and Weary, 2007), fleeing from people perceived as predators (Rushen et al., 2008), and competition over resources (DeVries and von Keyserlingk, 2006). We focus on the latter issue below, showing how research has identified methods of reducing the rates of competitive interactions in cattle.

The intensification of dairy cattle production has resulted in cows being housed at much higher stocking rates than in traditional grazing situations. Although aggressive interactions do take place on pasture (Phillips and Rind, 2002), these become much more common indoors, especially when cows are overcrowded (e.g., Orihuela and Galina, 1997) or regrouped (von Keyserlingk et al., 2008). For example, aggressive interactions at the feed bunk increased 2-fold in competitively fed transition cows compared with their noncompetitively fed counterparts (Proudfoot et al., 2009).

Gaining access to fresh feed is a high priority for cattle and is often paralleled with a high incidence of aggressive interactions (DeVries and von Keyserlingk, 2006). However, new work has shown that slight modifications to the feeding environment can dramatically reduce aggression. Providing more feeding space or installing partitions ("feed stalls") between adjacent cows protects them from competition, increasing feeding 
time and reducing the number of competitive displacements (DeVries and von Keyserlingk, 2006). The use of a barrier between teats has a similar effect in reducing aggression among group-housed calves (Jensen et al., 2008).

\section{CONCLUSIONS}

Until recently, many in the dairy industry may have assumed that animal welfare concerns could be met by working to ensure good health and productivity for the cows and calves in their care. We have argued that these aspects of biological functioning are indeed important aspects of welfare, but that this focus on measures of biological functioning is necessary but not sufficient; welfare issues also relate to affective states, such as pain or pleasure, and to concerns about naturalness, such as access to pasture. Animal welfare science attempts to address all 3 types of concerns by identifying problems in production systems and developing solutions to these problems. The best solutions are win-win, improving the lives of cattle and the people who work with them. The worst solutions are those that attempt to address one issue (such as a lack of pasture access) by creating another (exposing the cows to heat stress). We have reviewed a range of scientific research in this area to illustrate a variety of approaches and to give readers a better sense of current issues and how these can be addressed by science. High standards of animal welfare have been and will continue to be important to the dairy industry. It is our hope that this review will help provide a basis for a shared vision of what animal welfare means for our industry, and ultimately how welfare concerns can be identified and resolved.

\section{ACKNOWLEDGMENTS}

The paper reviews concepts and data generated by colleagues in the University of British Columbia Animal Welfare Program, including David Fraser and our many past and current graduate students. The Animal Welfare Program is funded by Canada's Natural Sciences and Engineering Research Council (Ottawa, Ontario, Canada) Industrial Research Chair Program with industry contributions from the Dairy Farmers of Canada (Ottawa, Ontario, Canada), Westgen Endowment Fund (Milner, British Columbia, Canada), Pfizer Animal Health (Kirkland, Québec, Canada), BC Cattle Industry Development Fund (Kamloops, British Columbia, Canada), the BC Milk Producers (Burnaby, British Columbia, Canada), BC Dairy Foundation (Burnaby, British Columbia, Canada), BC Dairy Education and Research Association (Abbotsford, British
Columbia, Canada), and Alberta Milk (Edmonton, Alberta, Canada).

\section{REFERENCES}

Bernardi, F., J. Fregonosi, D. M. Veira, C. Winkler, M. A. G. von Keyserlingk, and D. M. Weary. 2009. The stall design paradox: Neck rails increase lameness but improve udder and stall hygiene. J. Dairy Sci. 92:3074-3080.

Bertenshaw, C. E., P. R. Rowlinson, H. L. Edge, S. Douglas, and R. Shiel. 2008. The effect of different degrees of 'positive' humananimal interaction during rearing on welfare and subsequent production of commercial dairy heifers. Appl. Anim. Behav. Sci. 114:65-75.

Boissy, A., G. Manteuffel, M. B. Jensen, R. O. Moe, B. Spruijt, L. J. Keeling, C. Winckler, B. Forkman, I. Dimitrov, J. Langbein, M. Bakken, I. Veissier, and A. Aubert. 2007. Assessment of positive emotions in animals to improve their welfare. Physiol. Behav. 92:375-397.

Borderas, T. F., J. Rushen, and A. M. de Passillé. 2008b. Behavioral effects of endotoxin-induced fever in dairy calves. J. Anim. Sci. $86: 2920-2927$.

Borderas, T. F., A. Fournier, J. Rushen, and A. M. B. de Passille. 2008a. Effect of lameness on dairy cows' visits to automatic milking systems. Can. J. Anim. Sci. 88:1-8.

Bruckmaier, R. M., and J. W. Blum. 1998. Oxytocin release and milk removal in ruminants. J. Dairy Sci. 81:939-949.

Channon, A. J., A. M. Walker, T. Pfau, I. M. Sheldon, and A. M. Wilson. 2009. Variability of Manson and Leaver locomotion scores assigned to dairy cows by different observers. Vet. Rec. 164:388392.

Colditz, I. G. 2002. Effects of the immune system on metabolism: Implications for production and disease resistance in livestock. Livest. Prod. Sci. 75:257-268.

Cook, N. B., and K. V. Nordlund. 2009. Review: The influence of the environment on dairy cow behavior, claw health and herd health lameness dynamics. Vet. J. 179:360-369.

Dawkins, M. S. 2008. The science of animal suffering. Ethology 114:937-945.

de Passillé, A. M., R. J. Christopherson, and J. Rushen. 1993. Nonnutritive sucking and the postprandial secretion of insulin, CCK and gastrin in the calf. Physiol. Behav. 54:1069-1073.

de Passillé, A. M. B., and J. Rushen. 2006. Calves' behaviour during nursing is affected by feeding motivation and milk availability. Appl. Anim. Behav. Sci. 101:264-275.

DeVries, T. J., and M. A. G. von Keyserlingk. 2006. Effects of feeder design on the social and feeding behaviour of lactating dairy cows. J. Dairy Sci. 89:3522-3531.

Diaz, M. C., M. E. Van Amburgh, J. M. Smith, J. M. Kelsey, and E. L. Hutten. 2001. Composition of growth of Holstein calves fed milk replacer from birth to 105-kilogram body weight. J. Dairy Sci. 84:830-842.

Eicher, S. D., H. W. Cheng, A. D. Sorrells, and M. M. Schutz. 2006. Short communication: Behavioral and physiological indicators of sensitivity or chronic pain following tail docking. J. Dairy Sci. 89:3047-3051.

Færevika, G., I. L. Andersen, M. B. Jensen, and K. E. Bøe. 2007. Increased group size reduces conflicts and strengthens the preference for familiar group mates after regrouping of weaned dairy calves (Bos taurus). Appl. Anim. Behav. Sci. 108:215-228.

Fleischer, P., M. Metzner, M. Beyerbach, M. Hoedemaker, and W. Klee. 2001. The relationship between milk yield and the incidence of some diseases in dairy cows. J. Dairy Sci. 84:2025-2035.

Flower, F. C., D. J. Sanderson, and D. M. Weary. 2005. Hoof pathologies influence kinematic measures of dairy cow gait. J. Dairy Sci. 88:3166-3175.

Flower, F. C., and D. M. Weary. 2003. The effects of early separation on the dairy cow and calf. Anim. Welf. 12:339-348. 
Flower, F. C., and D. M. Weary. 2009. Gait assessment in dairy cattle. Animal 3:87-95.

Fraser, D. 2003. Assessing animal welfare at the farm and group level: The interplay of science and values. Anim. Welf. 12:433-443.

Fraser, D. 2008. Understanding Animal Welfare: The Science in Its Cultural Context. Wiley-Blackwell, Oxford, UK.

Fraser, D., D. M. Weary, E. A. Pajor, and B. N. Milligan. 1997. A scientific conception of animal welfare that reflects ethical concerns. Anim. Welf. 6:187-205.

Goff, J. P. 2006. Major advances in our understanding of nutritional influences on bovine health. J. Dairy Sci. 89:1292-1301.

González, L. A., B. J. Tolkamp, M. P. Coffey, A. Ferret, and I. Kyriazakis. 2008. Changes in feeding behavior as possible indicators for the automatic monitoring of health disorders in dairy cows. J. Dairy Sci. 91:1017-1028.

Gröhn, Y. T., P. J. Rajala-Schultz, H. G. Allore, M. A. DeLorenzo, J. A. Hertl, and D. T. Galligan. 2003. Optimizing replacement of dairy cows: Modeling the effects of diseases. Prev. Vet. Med. $61: 27-43$

Hammon, D. S. I. M. Evjen, T. R. Dhiman, J. P. Goff, and J. L. Walters. 2006. Neutrophil function and energy status in Holstein cows with uterine health disorders. Vet. Immunol. Immunopathol. $113: 21-29$

Hammon, H. M., G. Schiessler, A. Nussbaum, and J. W. Blum. 2002 Feed intake patterns, growth performance, and metabolic and endocrine traits in calves fed unlimited amounts of colostrum and milk by automate, starting in the neonatal period. J. Dairy Sci. 85:3352-3362

Hänninen, L., H. Hepola, S. Raussi, and H. Saloniemi. 2008. Effect of colostrum feeding method and presence of dam on the sleep, rest and sucking behaviour of newborn calves. Appl. Anim. Behav. Sci. 112:213-222.

Heinrich, A., T. F. Duffield, K. D. Lissemore, E. J. Squires, and S. T. Millman. 2009. The impact of meloxicam on postsurgical stress associated with cautery dehorning. J. Dairy Sci. 92:540-547.

Hemsworth, P. H., J. L. Barnett, L. Beveridge, and L. R. Matthews. 1995. The welfare of extensively managed dairy cattle: A review. Appl. Anim. Behav. Sci. 42:161-182.

Hernandez-Mendo, O., M. A. G. von Keyserlingk, D. M. Veira, and D. M. Weary. 2007. Effects of pasture on lameness in dairy cows. J. Dairy Sci. 90:1209-1214.

Huzzey, J. M., D. M. Veira, D. M. Weary, and M. A. G. von Keyserlingk 2007. Prepartum behavior and dry matter intake identify dairy cows at risk for metritis. J. Dairy Sci. 90:3220-3233.

Ingvartsen, K. L., R. J. Dewhurst, and N. C. Friggens. 2003. On the relationship between lactational performance and health: Is it yield or metabolic imbalance that cause production diseases in dairy cattle? A position paper. Livest. Prod. Sci. 83:277-308.

Jensen, M. B. 2006. Computer-controlled milk feeding of group-housed calves: The effect of milk allowance and weaning type. J. Dairy Sci. 89:201-206.

Jensen, M. B., A. M. de Passillé, M. A. G. von Keyserlingk, and J Rushen. 2008. A barrier can reduce competition over teats in pairhoused milk-fed calves. J. Dairy Sci. 91:1607-1613.

Kelm, S. C., and A. E. Freeman, and NC-2 Technical Committee. 2000. Direct and correlated responses to selection for milk yield: Results and conclusions of Regional Project NC-2, "Improvement of dairy cattle through breeding, with emphasis on selection." J. Dairy Sci. 83:2721-2732.

Kung, L. Jr., S. Demarco, L. N. Siebenson, E. Joyner, G. F. W. Haenlein, and R. M. Morris. 1997. An evaluation of two management systems for rearing calves fed milk replacer. J. Dairy Sci. 80:2529-2533.

Lean, I. J., C. T. Westwood, and M. C. Playford. 2008. Livestock disease threats associated with intensification of pastoral dairy farming. N. Z. Vet. J. 56:261-269.

Legrand, A. L., M. A. G. von Keyserlingk, and D. M. Weary. 2009 Preference and usage of pasture versus free-stall housing by lactating dairy cattle. J. Dairy Sci. 92:3651-3658.

Millman, S. T. 2007. Sickness behaviour and its relevance to animal welfare assessment at the group level. Anim. Welf. 16:123-125.
World Organization for Animal Health. 2008. Introduction to the recommendations for animal welfare. Article 7.1.1.Pages 235-236 in Terrestrial Animal Health Code 2008. World Organization for Animal Health (OIE), Paris, France.

Orihuela, A., and C. S. Galina. 1997. Social order measured in pasture and pen conditions and its relationship to sexual behavior in Brahman (Bos indicus) cows. Appl. Anim. Behav. Sci. $52: 3-11$

Pastell, M. E., and M. Kujala. 2007. A probabilistic neural network model for lameness detection. J. Dairy Sci. 90:2283-2292.

Phillips, C. J. C., and M. I. Rind. 2002. The effects of social dominance on the production and behaviour of grazing dairy cows offered forage supplements. J. Dairy Sci. 85:51-59.

Proudfoot, K. A., D. M. Veira, D. M. Weary, and M. A. G. von Keyserlingk. 2009. Competition at the feed bunk changes the feeding, standing, and social behavior of transition dairy cows. J. Dairy Sci. 92:3116-3123.

Rauw, W. M., E. Kanis, E. N. Noordhuizen-Stassen, and F. J. Grommers. 1998. Undesirable side effects of selection for high production efficiency in farm animals: A review. Livest. Prod. Sci. 56:15-33.

Rushen, J., A. M. de Passillé, M. A. G. von Keyserlingk, and D. M. Weary. 2008. The Welfare of Cattle. Springer, Dordrecht, the Netherlands.

Rushen, J., L. Munksgaard, P. G. Marnet, and A. M. de Passillé. 2001. Human contact and the effects of acute stress on cows at milking. Appl. Anim. Behav. Sci. 73:1-14.

Schreiner, D. A., and P. L. Ruegg. 2002. Effects of tail docking on milk quality and cow cleanliness. J. Dairy Sci. 85:2503-2511.

Schütz, K. E., A. R. Rogers, N. R. Cox, and C. B. Tucker. 2009. Dairy cows prefer shade that offers greater protection against solar radiation in summer: Shade use, behaviour, and body temperature. Appl. Anim. Behav. Sci. 116:28-34.

Shamay, A., D. Werner, U. Moallem, H. Barash, and I. Bruckental. 2005. Effect of nursing management and skeletal size at weaning on puberty, skeletal growth rate and milk production during first lactation of dairy heifers. J. Dairy Sci. 88:1460-1469.

Song, X., T. Leroy, E. Vranken, W. Maertens, B. Sonck, and D. Berckmans. 2008. Automatic detection of lameness in dairy cattleVision-based trackway analysis in cow's locomotion. Comput. Electron. Agric. 64:39-44.

Špinka, M. 2006. How important is natural behaviour in animal farming systems? Appl. Anim. Behav. Sci. 100:117-128.

Stafford, K. J., and D. J. Mellor. 2005. Dehorning and disbudding distress and its alleviation in calves. Vet. J. 169:337-349.

Stilwell, G., R. C. de Carvalho, M. S. Lima, and D. M. Broom. 2009. Effect of caustic paste disbudding, using local anaesthesia with and without analgesia, on behaviour and cortisol of calves. Appl. Anim. Behav. Sci. 116:35-44.

Svensson, C., and M. B. Jensen. 2007. Short communication: Identification of diseased calves by use of data from automatic milk feeders. J. Dairy Sci. 90:994-997.

Tadich, N., E. Flor, and L. Green. 2009. Associations between hoof lesions and locomotion score in 1098 unsound dairy cows. Vet. J. doi:10.1016/j.tvjl.2009.01.005

Thomas, T. J., D. M. Weary, and M. C. Appleby. 2001. Newborn and 5-week-old calves vocalize in response to milk deprivation. Appl. Anim. Behav. Sci. 74:165-173.

Tom, E. M., I. J. H. Duncan, T. M. Widowski, K. G. Bateman, and K. E. Leslie. 2002b. Effects of tail docking using a rubber ring with or without anesthetic on behavior and production of lactating cows. J. Dairy Sci. 85:2257-2265.

Tom, E. M., J. Rushen, I. J. H. Duncan, and A. M. de Passillé. 2002a. Behavioural, health and cortisol responses of young calves to tail docking using a rubber ring or docking iron. Can. J. Anim. Sci. $82: 1-9$.

USDA. 2007. Dairy 2007, Part I: Reference of Dairy Cattle Health and Management Practices in the United States, 2007. No. N480.1007. USDA-Anim. Plant Health Inspection Serv.-Vet. Serv., Centers Epidemiol. Anim. Health, Fort Collins, CO. 
USDA. 2009. Dairy 2007, Part IV: Reference of Dairy Cattle Health and Management Practices in the United States, 2007. No. N494.0209. USDA-Anim. Plant Health Inspection Serv.-Vet. Serv., Centers Epidemiol. Anim. Health, Fort Collins, CO.

Vanegas, J., M. Overton, S. L. Berry, and W. M. Sischo. 2006. Effect of rubber flooring on claw health in lactating dairy cows housed in free-stall barns. J. Dairy Sci. 89:4251-4258.

Veissier, I., A. Butterworth, B. Bock, and E. Roe. 2008. European approaches to ensure good animal welfare. Appl. Anim. Behav. Sci. 113:279-297.

Vickers, K. J., L. Niel, L. M. Kiehlbauch, and D. M. Weary. 2005. Calf response to caustic paste and hot-iron dehorning using sedation with and without local anesthetic. J. Dairy Sci. 88:1454-1459.

Vieira, A. D., V. Guesdon, A. M. de Passillé, M. A. G. von Keyserlingk, and D. M. Weary. 2008. Behavioural indicators of hunger in dairy calves. Appl. Anim. Behav. Sci. 109:180-189.

von Keyserlingk, M. A. G., D. Olenick, and D. M. Weary. 2008. Acute behavioral effects of regrouping dairy cows. J. Dairy Sci. 91:10111016 . von Keyserlingk, M. A. G., and D. M. Weary. 2007. Maternal behaviour in cattle: A review. Horm. Behav. 52:106-113.

Washburn, S. P., S. L. White, J. T. Green Jr., and G. A. Benson. 2002. Reproduction, mastitis, and body condition of seasonally calved Holstein and Jersey cows in confinement or pasture systems. J. Dairy Sci. 85:105-111.

Weary, D. M., J. M. Huzzey, and M. A. G. von Keyserlingk. 2009 Board-invited review: Using behavior to predict and identify ill health in animals. J. Anim. Sci. 87:770-777.

Weary, D. M., L. Niel, F. C. Flower, and D. Fraser. 2006. Identifying and preventing pain in animals. Appl. Anim. Behav. Sci. 100:6476.

Whay, H. R., D. C. J. Main, L. E. Green, and A. J. F. Webster. 2003. Assessment of the welfare of dairy cattle using animal-based measurements: Direct observations and investigation of farm records. Vet. Rec. 153:197-202. 